\title{
The Spatial Limits of Environmental Benefit of Industrial Symbiosis - Life Cycle Assessment Study
}

\author{
Andrzej Marcinkowski \\ Faculty of Management and Production Engineering, Division of Fundamentals of Industrial Ecology and \\ Engineering, Lodz University of Technology, Stefana Żeromskiego 116, Łódź, Poland \\ e-mail: andrzej.marcinkowski@p.lodz.pl
}

Cite as: Marcinkowski, A., The Spatial Limits of Environmental Benefit of Industrial Symbiosis - Life Cycle Assessment Study, J. sustain. dev. energy water environ. syst., 7(3), pp 521-538, 2019, DOI: https://doi.org/10.13044/j.sdewes.d7.0270

\begin{abstract}
Industrial ecosystems are supposed to improve environmental performance. However, despite proven financial profitability, environmental justification of particular symbiotic initiatives is not obvious and demands verification. The authors of previous studies have recommended application of life cycle assessment method for environmental impact estimation in case of industrial symbiosis. However, few studies presenting life cycle assessment results of industrial symbiosis have been published so far. Among the factors which contribute to the success of symbiotic exchange, the close location of collaborating companies has been often mentioned in the literature. Most researches have focused on single industrial ecosystem where cooperating companies were located relatively close to each other. The positive environmental impact of particular symbiotic initiatives has been verified, however, the results have not provided more a general conclusion for other industrial ecosystems, including virtual eco-industrial parks. The main aim of this work was to determine the maximum distance of symbiotic transmission at which the environmental impact remains positive. Life cycle assessment results concerning the environmental impact of symbiotic fly ash exchange were presented. Concepts of relative distance and critical distance for the case of industrial symbiosis were proposed and defined. Considerable differences between critical distance obtained for particular endpoints were observed. The mixing triangle method was applied to estimate the critical distance taking into account individual impact categories. The final results pointed out that the critical distance of symbiotic fly ash exchange was much longer than in case of gypsum transmission. A sensitivity analysis indicated the relationship between critical distance and the means of transport which reflected the effect of scale. The effect of fly ash pre-processing on the results was examined, and it turned out to be insignificant.
\end{abstract}

\section{KEYWORDS}

Industrial symbiosis, Life cycle assessment, Coal fly ash, By-product exchange, Environmental performance, Industrial ecology, Environmental benefit, Waste utilization, Transportation distance.

\section{INTRODUCTION}

The development of industrial ecosystems is one of the most promising and available ways to embody the concept of sustainable development [1]. The business model of industrial symbiosis, defined as collaboration between companies whereby the wastes or 
by-products of one become a resource for another, has been identified as a key factor enabling the move towards a circular economy [2].

The most important idea of industrial symbiosis is transfer of by-products or waste flows generated by one company to another one in order to use them for production purposes instead of natural resources. Industrial symbiosis involves cooperation aimed at achieving a competitive advantage by taking advantage of the synergy effect resulting from the close proximity of industrial plants of collaborating companies [3]. Close distance between enterprises is a very important factor for the success of symbiotic connections [4]. Since the distance has a direct impact on transport costs of by-products, in case of too long distances, transport cost could exceed the economic value of waste flow being exchanged and cooperation would not be profitable. Instead, low transportation cost encourages symbiotic actions [5].

As the symbiotic initiatives are supposed to improve environmental performance, apart from financial profitability, environmental benefits and losses should be also assessed. The use of waste as a raw material certainly brings environmental benefits. However, the required transport causes an additional environmental burden. If the distance between the cooperating companies is too long, the environmental balance becomes negative and the symbiotic connection between them would lose its environmental justification.

The environmental balance of a single symbiotic relationship is determined by a number of components, such as: avoided treatment or disposal of waste, avoided production and reduced use of virgin materials or energy, transportation of waste, and pre-processing with associated technological modification for using the acquired waste flow (if necessary) [6]. The first two components represent a positive influence on the environment. The third one (transportation) may also bring environmental benefit, especially when the distance between collaborating industries is closer compared to the distance to waste disposal place.

Since sustainable development involves multidisciplinary aspects, various initiatives to implement this concept require complex methods and tools to measure and compare the environmental impacts of industrial activities to verify the real improvement of environmental performance [7]. And thus, in the case of symbiotic initiatives the appropriate method to determine the total environmental impact should consider different variables (associated not only with benefit but also burden). Moreover, since industrial symbiosis consists in a cooperation between companies, the environmental balance assessment should not be limited to impacts of one separate company. A much wider approach is needed in order to take into account all environmental impacts of the entire supply chains from material extraction to waste disposal [8] and avoid the possibility of "pollution transfer" from one industrial plant to another and environmental burden shifting between different environmental impact categories [9]. The method meeting the above conditions is Life Cycle Assessment (LCA) that is a powerful set of tools for quantifying, evaluating, comparing, and improving products or systems in terms of their potential environmental aspects. LCA supports the identification of opportunities for pollution prevention and enables to verify the environmental justification of initiatives which are intuitively green [7]. Since LCA can provide vital information about the overall environmental performance of industrial systems, it is a recommended method for environmental impact assessment in case of industrial symbiosis [1]. The authors expressed the need to use a full LCA to analyze industrial ecosystems together with their global connections within the whole supply chain [10]. However, so far only a few studies have applied LCA to assess the benefits of industrial symbiosis [11]. The juxtaposition and classification of LCA application for circular economy initiatives have been presented by Mattila et al. [12]. The examples of recently published articles including such research are reported below. 
LCA method has been applied to assess the environmental impact of Xinfa Group industrial ecosystem located in the Chinese Province of Shandong. The analyzed collaboration network consisted of 11 entities exchanging a number of by-products, e.g. coal ash as a raw material for brick production, desulfurization gypsum as a substitute for natural gypsum, carbide slag used as a raw material in alumina production, carbon monoxide which was burned to supply energy for the lime factory, the red mud that was reused as a building material after iron, aluminum, and sodium hydrate extraction, energy and water. The existing industrial ecosystem has been compared to a reference scenario assuming separate activity of single industries with no symbiotic connections. The environmental performance has been analyzed for four impact categories: primary energy consumption, greenhouse gas emissions, acidification, and eutrophication. The research results have pointed out that the symbiotic exchange provided primary energy savings and emission reduction of carbon dioxide $\left(\mathrm{CO}_{2}\right)$, sulfur dioxide $\left(\mathrm{SO}_{2}\right)$, and phosphate $\left(\mathrm{PO}_{4}\right)$ equivalents. The most visible benefits have resulted from comprehensive utilization of red mud and energy conservation [13].

Substantial benefit of energy exchange has also been reported in the LCA analysis of Songmudao industrial park located in Dalian, China. The chemical cluster has consisted of seven businesses exchanging energy, water, liquid ammonia, ammonium sulfate, wastewater, sludge, fly ash, slag, carbon monoxide $(\mathrm{CO})$ transformed sewage and $\mathrm{CO}_{2}$. The model of environmental balance included avoided production and reduced use of raw materials, any necessary pre-processing or transport, and avoided treatment or disposal of by-products. Four impact categories: primary energy consumption, greenhouse gas emissions, acidification, and eutrophication were analyzed to assess the environmental impact. All exchanges exhibited positive effect across all impact categories. The greatest benefit was exhibited by steam transmission followed by materials and water exchange [14]. Considerable contribution of energy exchange in relation to the total environmental benefit has earlier been reported by other authors. Sokka et al. [15] have studied the industrial ecosystem developed around an integrated pulp and paper manufacturer situated in the Finnish town of Kouvola. The analysis of various by-product exchanges, such as heat, electricity, water, sewage sludge, wastewater, ash, waste, hydrogen peroxide, calcium carbonate, carbon dioxide, chlorine, chlorine dioxide, sodium hydroxide, and biomaterials has shown that most of the benefits occurred upstream through heat and electricity production. Similar conclusion has been drawn by Eckelman and Chertow [6]. The authors have described the symbiotic network existing in Campbell industrial park in Honolulu, Hawaii. The network involved exchange of 14 by-product flows such as water, steam, sewage sludge, waste oil, shredded tires, fly ash, mixed ash and granular activated carbon. LCA results have shown that all symbiotic exchanges (except for the waste oil and shredded tires) brought net environmental benefits. The steam utilization exhibited the greatest benefit.

LCA has also been used to measure the environmental benefits of industrial ecosystem developed within the area of $240 \mathrm{~km}^{2}$ in a tannery cluster located in Tuscany, Italy. Not only waste recovery initiatives have been considered but also common services associated with collective wastewater treatment. Two scenarios have been compared: existing collaboration network vs. the same cluster where symbiotic initiatives were less developed. Environmental performance has been determined for 16 impact categories. The indicators of all the categories have pointed out the environmental benefit resulting from industrial symbiosis. The relative impact reduction ranged from $1.5 \%$ to $21.9 \%$ ( $9.1 \%$ on average). On the basis of the presented results, the authors recommended to the political authorities to use the cluster approach for development of industrial symbiosis as an instrument for environmental impact optimization both at the local and regional levels. LCA has been suggested as a tool for cluster managers to support decision-making processes aiming at cluster development [11]. 
The analyses of symbiotic exchange network can have extended scope and include not only industries but also nearby residential districts. The urban industrial ecosystem centered around the city of Liuzhou, China, was studied by Dong et al. [16]. The hybrid evaluation model (input-output LCA) was constructed and applied to quantify environmental impact of urban symbiosis and compare it with the reference scenario (linear processes). The model was focused on changes in $\mathrm{CO}_{2}$ emission associated with up-stream material consumption, power consumption, waste disposal and cross-boundary transport. Five by-products utilization initiatives, such as: recycling of waste plastic, scrap tire, fly ash, as well as biomass utilization and carbon capture by slag carbonization, were analyzed. The results showed that all by-product exchanges reduced $\mathrm{CO}_{2}$ emission. The greatest improvement was recorded in case of biomass utilization. The research showed that urban industrial symbiosis was an opportunity to reduce the environmental impact of industry, moreover such initiatives contributed to the city development. The Liuzhou urban symbiotic network was also studied by Sun et al. [17]. The emergy approach, as defined by Sun et al. [17], is a concept to reflect differences between various forms of energy. The environmental benefit was measured by combining material flow analysis and emergy approach. Two scenarios were analyzed, as in the work referred to above. The results indicated that urban industrial symbiosis saved $12 \%$ of total emergy consumption.

Some studies focused on environmental impact of utilization of one specific waste type as a case of single symbiotic initiative. An example is the survey concerning the application of fine glass powder from mixed waste glass as cementitious materials in concrete production for sidewalk construction. The environmental impact was quantified by means of IMPACT 2002+ method determining 15 midpoint categories converted into 4 endpoint indicators: human health, climate change, natural resources, and ecosystem quality. The waste utilization environmental feasibility was examined by comparison to the reference scenario - a standard concrete production. The indicators obtained showed that the symbiotic scenario reduced the environmental impact in terms of all impact categories. The greatest benefit was associated with alternative cementitious materials in concrete production. The results also showed the importance of transportation distance of the main concrete ingredients (sand, gravel, and cement). Extension of the distance by $300 \mathrm{~km}$ had a very significant influence on the results - for most endpoint indicators the total environmental impact exceeded the impact of the reference scenario mostly because of the fuel consumption [18]. According to the insight reported here, it could be concluded that initiatives of industrial symbiosis do not always provide sustainability improvements. A similar conclusion was drawn from the research of Mohammed et al. [19]. The authors applied LCA (a cradle to gate approach) to assess the environmental impact of phosphogypsum utilization as a raw material for paper and fertilizers production. Five scenarios representing different reaction reagents and pathways were selected for analysis. The results were reported in terms of three impact categories: global warming potential, eutrophication potential and solid waste impact resulting from the waste processing. The study found that the phosphogypsum utilization worsened environmental performance regardless of whether it was used for paper or fertilizers production.

On the basis of the literature review discussed above, a number of key conclusions can be drawn. Environmental benefit of particular symbiotic initiatives has not been obvious and required verification. The life cycle perspective has been recommended to quantify the environmental impact of by-products utilization. However, few studies presenting LCA results of industrial symbiosis have been published so far [11]. Most studies addressed single industrial ecosystem where cooperating companies were located relatively close to each other. The influence of the distance between collaborating industries on environmental performance was usually not investigated. Some authors 
assumed that avoided transportation of waste to the disposal location and additional by-product transmission were approximately equivalent, excluding the environmental impact of local transport from consideration [6]. Most LCA analyses provided an ecological justification of particular symbiotic exchanges. The greatest environmental benefit often resulted from energy utilization. However, in some cases environmental losses of symbiotic initiatives were reported [19], or the total impact was basically positive but became negative when longer transportation distance was assumed [18]. Such an observation arouses interest in the effect of the distance between cooperating industries on the environmental impact, and leads to the question what is the spatial limit of industrial symbiosis. Usually in the case of analysis of existing symbiotic networks the transportation distance between companies is known and may result in a fixed environmental impact. To obtain more general conclusion, the main objective of this study is to estimate the maximum distance of a particular by-product exchange at which the symbiotic initiative remains justified from environmental point of view. Filling this literature gap could answer to what extent the distance of symbiotic collaboration may be increased while remaining the initiative environmentally beneficial. This is particularly relevant in view of virtual eco-industrial parks where symbiotic exchanges take place despite lack of proximity between involved plants. This is also important in case of single utilization initiatives where the waste producer collaborates with a distant business, and despite the long distance, the cooperation is mutually beneficial, otherwise, local waste disposal would demand higher cost. In the above cases, irrespective of the financial profitability, environmental benefit can be outweighed by the loss due to the impact of waste transport. Such an undesirable situation may be less likely in the case of symbiotic initiatives which demonstrate considerable ecological benefit (electricity, heat utilization). Outweighing the exchange benefits by the impact of transport can be anticipated to be more likely in case of other power station's by-product such as desulfurization gypsum or Coal Fly Ash (CFA). This study, therefore, focuses on estimation of spatial limits of industrial symbiosis for fly ash exchange by means of LCA method. Outcomes of analogous analysis concerning gypsum exchange [20] will be also summarized and compared to the results of the present work.

\section{METHODS}

One of the typical by-products of inter-company transfers within industrial ecosystems is fly ash due to the fact that often a vital role in the symbiotic network is played by a coal-fired power plant, e.g. Kalundborg, Denmark [21], Kymenlaakso, Finland [22], Norte Fluminense region, Brazil [23], Guigang, China [24], Xinfa Group, Shandong, China [13].

There are various types of fly ash. This study concerns CFA which is defined as fine powder of mainly spherical, glassy particles, derived from burning of pulverized coal, which has pozzolanic properties and consists essentially of silicon dioxide $\left(\mathrm{SiO}_{2}\right)$ and aluminium oxide $\left(\mathrm{Al}_{2} \mathrm{O}_{3}\right)$ and which is obtained by electrostatic or mechanical precipitation of dust-like particles from the flue gases of the power stations [25].

There are a number of reasons to utilize fly ash: minimization of disposal costs, reduction of area reserved for disposal, financial income from the sale of the by-product, and substitution of natural resources [26]. Most annual fly ash production in Europe is disposed, stockpiled or used for mine restoration. Quite a significant proportion of fly ash - 47\% - is, however, utilized. CFA is predominantly used as a substitute for raw materials in the construction industry. According to the main utilization directions, fly ash is used as partial replacement for clinker in Portland cement production (17\%), as an additive (replacement of cement) in the concrete industry $(15 \%)$ or in geotechnical applications (12\%) such as grouting, asphalt filler, sub-grade stabilisation, pavement base course, general engineering fill, structural fill, soil amendment, and infill [27]. 
According to the EN 450 standard, fly ash may be processed, for example by the classification, selection, sieving, drying, blending, grinding or carbon reduction, or by combination of these processes [25]. However, LCA studies of CFA utilization in construction industry (presented in the introduction to this work) have not specified any fly ash processing except for transport. Eckelman et al. [6] present the analysis of CFA utilization as a substitute for Portland cement. Ash disposal, cement production and cement transport were assumed as avoided processes but no additional process was reported. In the research of Yu et al. [13], fly ash use in brick production was studied but no additional process was considered. The same research model was applied by Zhang et al. [14] in CFA utilization analysis. Dong et al. [16] surveyed a fly ash substitution for cement (at 1:1 ratio). As the additional process, waste transportation covering a distance of $10 \mathrm{~km}$ was assumed. An electricity consumption was also mentioned $(5.7 \mathrm{kWh})$, however, no particular processing was specified. Following the previous analyses, the research model of the present work assumes direct utilization of CFA exhibiting pozzolanic properties as a substitute for natural pozzolanic material with no by-product pre-processing. However, the extent of environmental impact of potential fly ash pre-treatment is examined and reported in sensitivity analysis section. The transportation is supposed to be analyzed as a key factor in the assessment of spatial limits of symbiotic initiatives.

As it was stated in the introduction, determination of the environmental impact of industrial symbiosis requires quite a wide approach which makes it possible to consider upstream and downstream flows, and to quantify pollution transfer between individual impact categories. For this reason LCA has been carried out in the present study assuming a cradle to grave perspective.

LCA consists in a comprehensive analysis of the environmental impact associated with sequential phases of the analyzed object's life cycle, such as resources extraction, raw material processing, manufacturing, transport, use, and disposal. The basic principles of this method are standardized. Description of the specific LCA procedures are included in international standards for environmental management concerning requirements and guidelines [28] and principles and framework of LCA [29]. The main steps include the goal and scope definition, inventory analysis, impact assessment, and interpretation.

In this work, the subsequent sub-procedures of impact assessment (classification, characterisation, normalisation) have been carried out using the Eco-indicator 99 method by means of SimaPro software. The method has taken into consideration 11 midpoint categories aggregated into 3 endpoint indicators expressed in independent units: ecosystem quality [(Potentially Disappeared Fraction) PDF $\times \mathrm{m}^{2} \times$ year], human health [(Disability Adjusted Life-Years) (DALY)], resources [MJ of surplus energy].

Results obtained for individual impact categories are difficult to compare with each other without introduction of weighting coefficients. However, the weighting procedure involves arbitrary factor which should be avoided. The mixing triangle method is therefore applied in this study to take results for all endpoints into consideration. The method represents all possible combinations of relative weights that are attributed to outputs of three impact categories. All points within the triangle indicate unique weighting combinations whose relative weights always add up to $100 \%$. The application of this method results in graphical representation of two compared scenarios (e.g. symbiotic exchange vs. lack of industrial symbiosis). If the areas referring to both scenarios are equal, no alternative seems to be environmentally superior to the other. The weighting triangle may simplify and clarify the discussion about environmental impact comparison [30].

LCA of a single symbiotic connection implies determination of environmental impact separately for each component of the environmental balance. Thanks to this, the comparison of positive and negative part of the impact is possible so that the conclusion 
can be drawn to find out finally whether or not the analyzed symbiotic initiative is environmentally justified. According to the model chosen, fly ash produced in power plants was assumed to be used directly to substitute natural pozzolanic material without any additional preparation process. Thus, the balance of environmental benefits and losses of the symbiotic connection involved: the benefit of the use of CFA, the benefit of no need for waste disposal in landfill, the benefit of no need for transport waste to landfill, the loss of the need to transport the by-product to the place of utilization.

The last two balance components point out that, transport could contribute both to positive and negative environmental impact. In order to eliminate the dependence of the distance between power plant and heap or landfill (place where fly ash would be dumped) on the results, it has been assumed that regardless of the destination (collaborating company or dump place) the transport mean was the same. Thanks to this assumption a research model structure has been simplified including three components: the benefit of the use of CFA, the benefit of no need for waste disposal, the loss caused by fly ash transport over a relative distance $\left(d_{R}\right)$.

The relative distance $\left(d_{\mathrm{R}}\right)$ can be defined by eq. (1):

$$
d_{\mathrm{R}}=d_{\mathrm{S}}-d_{\mathrm{D}}
$$

where $d_{\mathrm{s}}$ is the distance between a power plant and the company which uses by-product and $d_{\mathrm{D}}$ is the distance between a power plant and the disposal place.

The above model assumptions result in a simple conclusion: if the distance to the landfill place is greater than the distance to the collaborating company $\left(d_{\mathrm{D}}>d_{\mathrm{S}}\right)$, the symbiotic initiative is always profitable from environmental perspective. Otherwise, the total environmental profitability depends on the relations between positive components of balance and environmental impact of transport. In order to make the objective of this study more precise, a definition of critical distance is proposed. The critical distance is defined as the maximum relative distance between industrial plants that results in a neutral (neither positive nor negative) environmental impact of symbiotic exchange. Exceeding this distance would result in negative environmental impact of symbiotic initiative.

The research model does not have to assume the amount of fly ash that is used, as all three components of the balance are proportional to it. The unit environmental impact is independent of this amount. However, in order to obtain specific numerical results, 1,000 tons of fly ash is assumed as the functional unit.

The environmental impact of transport contains vehicles' life cycle including production, operation (fuel consumption, emission), maintenance and disposal as well as construction, maintenance and disposal of roads. The impact intensity of the lorries is based on the European emission standards. The assumption is made that the vehicles comply with standard EURO5, EURO4 or EURO3 with the proportion 1:1:1, thus one third of tankers comply with EURO5, etc. The most common means of transport for fly ash are tankers. Since the typical capacity of tankers is 5-19 $t$, as a transport mean a mix of vehicles with total permissible mass from the range of 7.5-32 $\mathrm{t}$ is assumed. It is also assumed that the vehicles and roads also have other functions and are only partially used to transport fly ash. Data of industrial processes of production, disposal and transport has been taken from Ecoinvent database. European conditions has been assumed. The analysis carried out cover various scenarios that differ in particular parameters. The research procedure consists of 3 steps:

- Determination of normalization indicators for sample relative distance $(500 \mathrm{~km})$;

- Determination of the critical distances for particular categories: $d_{\mathrm{crR}}, d_{\mathrm{crHH}}$ and $d_{\mathrm{crEQ}}$ (additional analyses and result interpolations have been involved);

- Mixing triangle application to determine the critical distance considering all impact categories $d_{\text {cr }}$ (additional analyses and interpolations have been made to 
obtain the result for which a half of the triangle area indicated recommendation for symbiosis initiative).

\section{RESULTS AND DISCUSSION}

This section is dedicated to the assessment of the critical distance for fly ash symbiotic transmission. Additionally, the outcomes of LCA analysis concerning environmental performance of symbiotic gypsum exchange [20] are summarized to enable comparison of the results.

Figure 1 depicts the environmental impact of symbiotic fly ash exchange over a sample distance of $500 \mathrm{~km}$ in terms of relative normalisation indicators. In the category of resources, the results indicate negative environmental impact (the bars are situated mostly above the zero axis). In the other two categories, viz., human health and ecosystem quality, a positive environmental impact is observed (most of the bars are situated below zero). The presented results lead to the following conclusions: from the point of view of human health and ecosystem quality, the critical distance has not been exceeded (the critical distance is longer than $500 \mathrm{~km}$ ), from the resources perspective, the critical distance is less than $500 \mathrm{~km}$. This conclusion suggests performing separate analyses for individual categories.

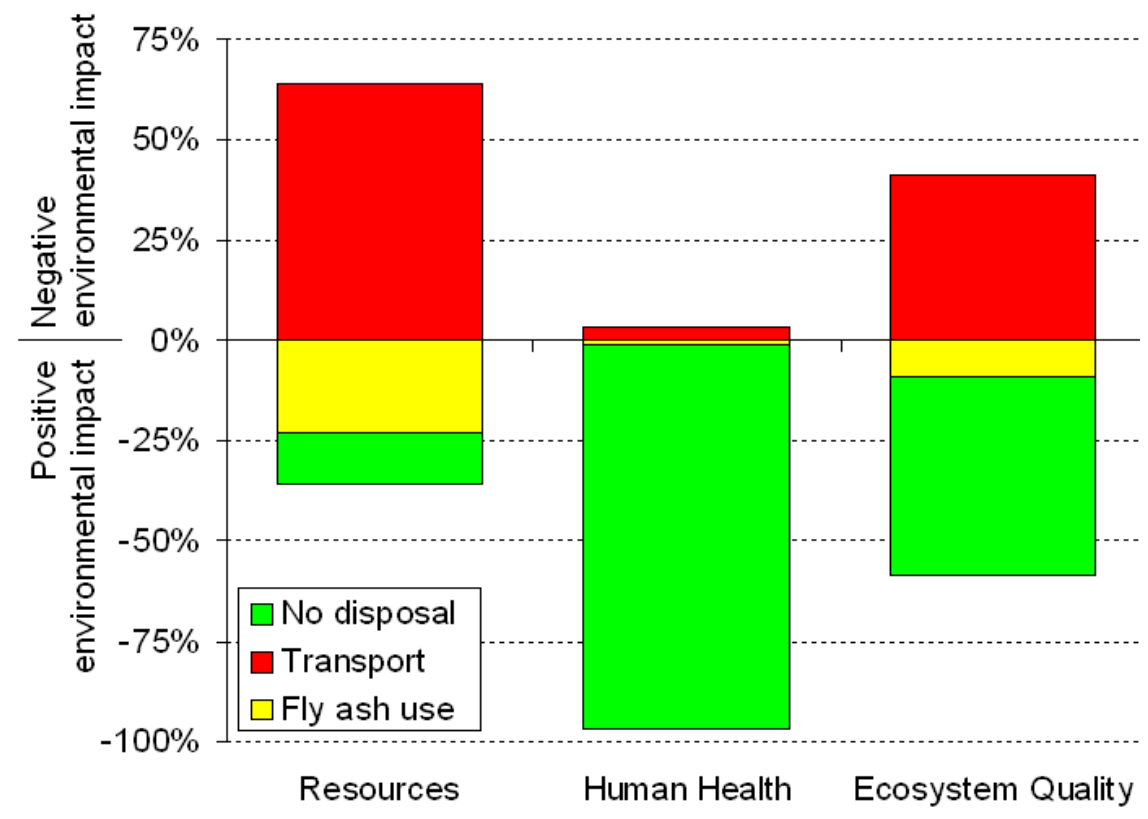

Figure 1. Indicators for symbiotic fly ash exchange over a distance of $500 \mathrm{~km}$

By additional analysis and interpolation, critical distances have been determined separately for different endpoints. Figure 2 presents process network for resources category for the scenario of symbiotic initiative involving fly ash transport over a critical distance $\left(d_{\mathrm{crR}}\right)$ (R subscript denotes resources category) of $279 \mathrm{~km}$. Positive (green arrows) and negative (red arrows) environmental impacts are balanced indicating that the critical distance has been obtained. An environmental benefit is predominated by fly ash use (64\% of total environmental benefit). The main components of the environmental burden are: operation of transport mean (79.6\%, including fuel consumption $75.7 \%)$, road construction (11.6\%), lorry manufacturing (3.3\%) and lorry maintenance $(3.8 \%)$. According to the assumption that the vehicles and roads also have other functions and are only partially used for fly ash transport, only a part of environmental impact of the vehicles and roads have been taken into account, proportional to the relative contribution of the symbiotic initiative to their total life cycle impact. 


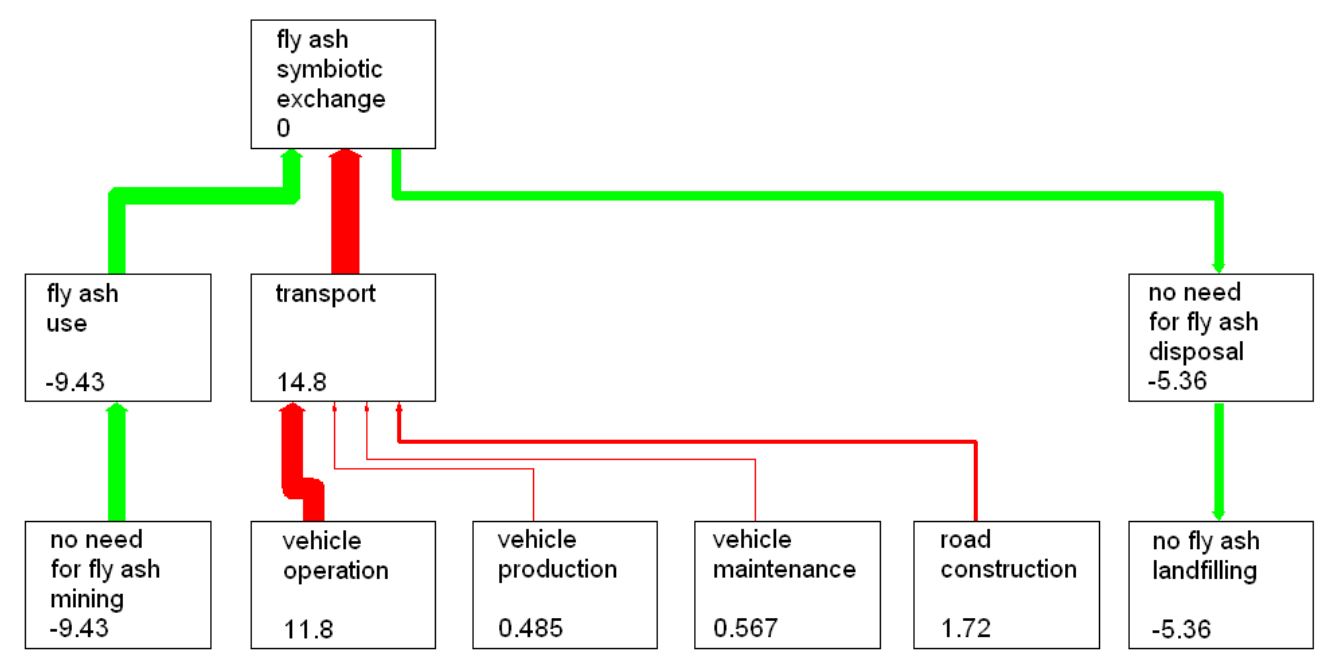

Figure 2. Process network for resources category for symbiotic fly ash exchange over a critical distance $\left(d_{\mathrm{crR}}\right)$

When it comes to the category of human health, a relatively long critical distance is expected $(>500 \mathrm{~km})$ due to the initial assessment. By means of results interpolation, the critical distance $\left(d_{\mathrm{crHH}}\right)$ was determined as $14,645 \mathrm{~km}$. The process network for the relevant scenario is depicted in Figure 3. An environmental benefit is strongly predominated by avoided disposal of fly ash (99\% of total environmental benefit). The main components of environmental loss resulting from transport are: operation of the vehicle $(74 \%$, including consumption of diesel oil - 15\%), vehicle manufacturing $(10.7 \%)$, vehicle maintenance $(3.0 \%)$, road construction $(11.3 \%)$, road maintenance $(1.6 \%)$. A difference between a particular component's contribution determined for both endpoints (resources and human health) can be observed. The most pronounced difference is visible in the environmental benefit structure. From human health perspective, the positive impact results mainly from avoided fly ash disposal, while from resources depletion's point of view, the impact of fly ash use predominates. A clear difference is also observed in impact structure of vehicle operation. From resources depletion's point of view, the most essential contribution was connected with fuel consumption (95\%), whereas from human health perspective the contribution of fuel use is far less important (20\%). Exhaust fume emission impact predominates in the latter case.

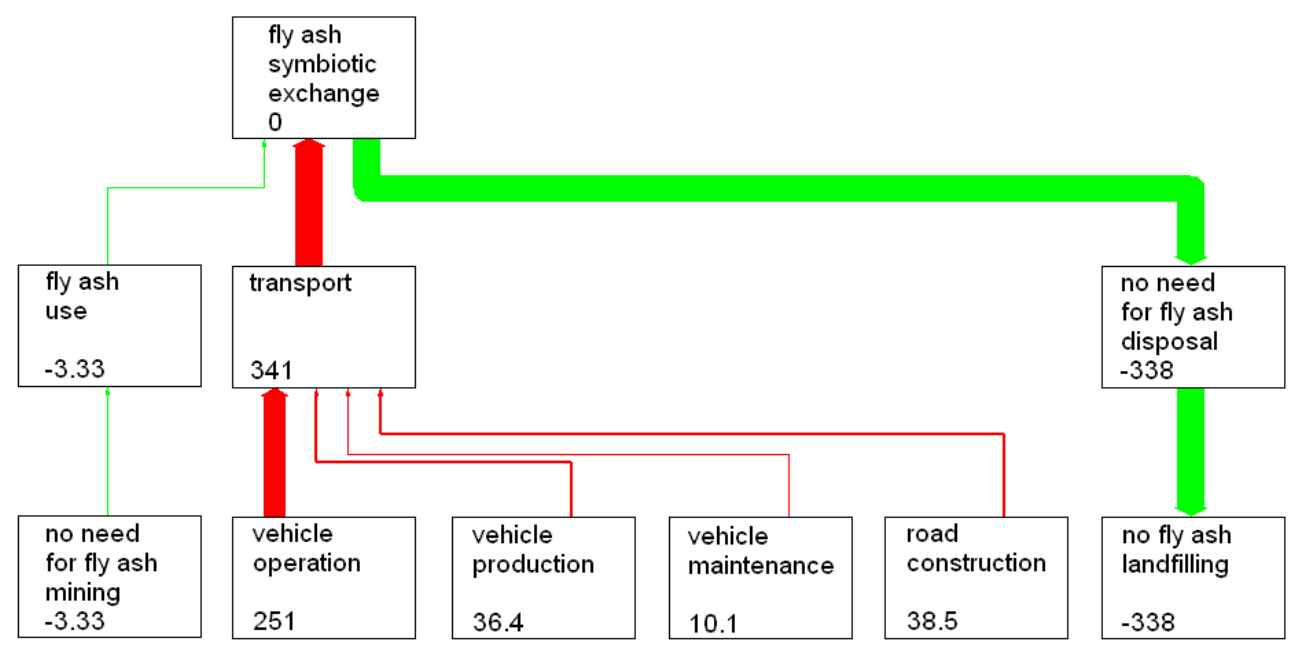

Figure 3. Process network for human health category for symbiotic fly ash exchange over a critical distance $\left(d_{\mathrm{crHH}}\right)$ 
In case of category of ecosystem quality, by means of results interpolation, the critical distance $\left(d_{\mathrm{crEQ}}\right)$ has been determined on the level of $708 \mathrm{~km}$. Figure 4 presents the process network for the scenario of symbiotic connection involving fly ash transport over the critical distance for ecosystem quality category. As in the case of the human health endpoint, avoided disposal of fly ash predominates within environmental benefits $(85 \%$ of total benefit). The most vital component of environmental load resulting from transport is vehicle operation $(70 \%)$ where fume emission impact predominates (as in the case of human health category). Apart from vehicle operation, the most significant negative impact results from road maintenance (12.6\%), road construction (7.1\%) lorry production and maintenance $(6.4 \%$ and $2.5 \%)$.

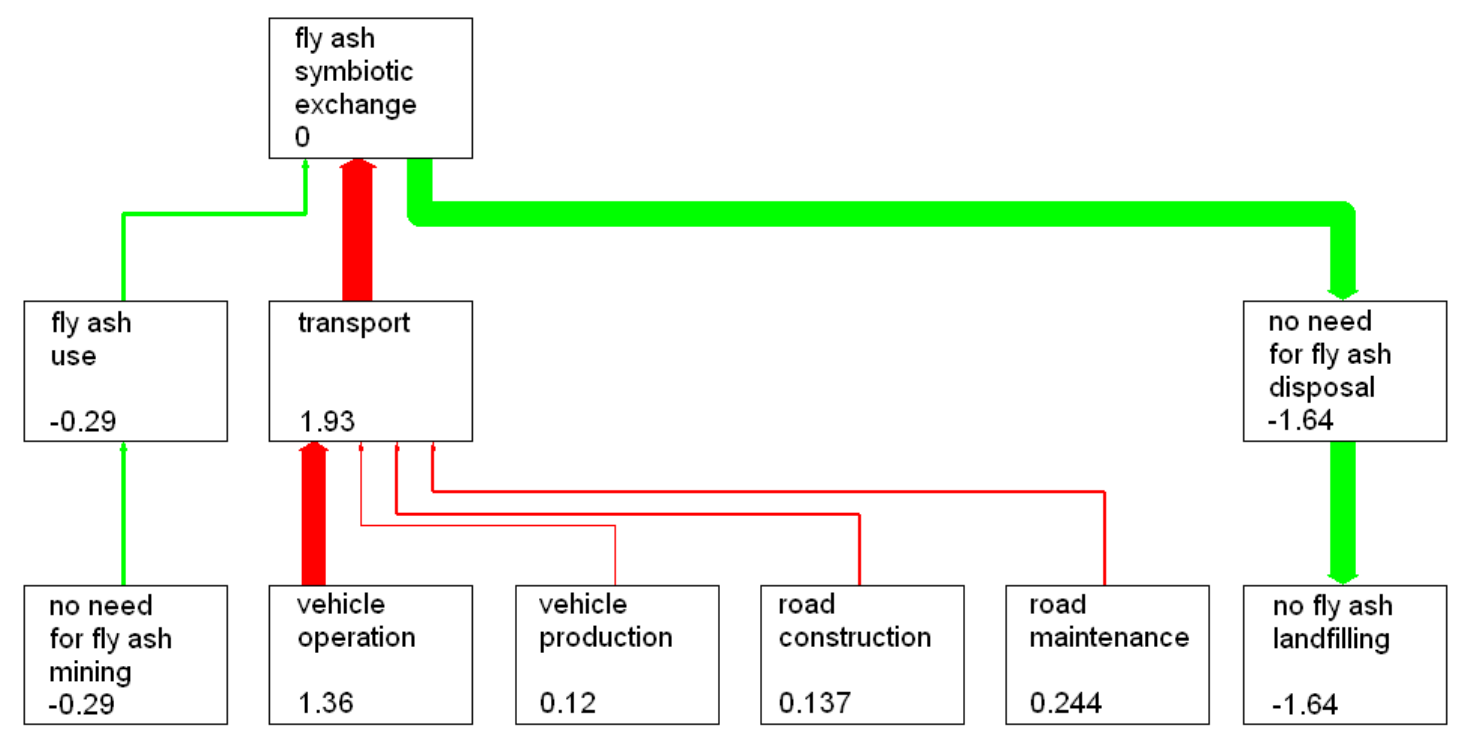

Figure 4. Process network for ecosystem quality category for symbiotic fly ash exchange over a critical distance $\left(d_{\mathrm{crEQ}}\right)$

As mentioned above, an analogous analysis concerning gypsum symbiotic exchange was carried out. The research model assumed average trucks with total permissible mass from the range of 3.5-28 $\mathrm{t}$ as a transport mean. The functional unit was 10,000 tons of gypsum. LCA procedures were performed by means of the Eco-indicator 99 method. A very wide range (over two orders of magnitude) of the critical distance has been determined for individual endpoints. In case of resources category, the critical distance reached $51.4 \mathrm{~km}$, environmental benefit was predominated by avoided disposal of gypsum ( $87 \%$ of total environmental benefit), whereas the environmental loss resulted mainly from trucks operation ( $81 \%$, including fuel production $67 \%)$. The greatest critical distance $(564 \mathrm{~km})$ was obtained for human health category, the benefit primarily occurred upstream in the system due to avoidance of natural gypsum extraction (89\%), within the environmental impact of transport, exhaust emission outweighed the rest of losses. In the case of ecosystem quality, the critical distance amounted to only $3.5 \mathrm{~km}$, environmental benefit was predominated by avoided gypsum extraction (84\%), and the environmental loss resulted mainly from trucks operation $(78 \%$ of total transport impact) [20].

The comparison of the results determined for the case of fly ash and gypsum exchange reveals significant differences. Although the greatest critical distance was obtained for the same endpoint (human health), the benefit resulted from different processes: avoided production for gypsum, and avoided landfilling when it comes to fly ash. Moreover, the minimum critical distance was observed for distinct impact categories: it was ecosystem quality in case of gypsum (the largest share in the benefit 
occurred upstream of the system), and resources category in the other case (with downstream processes domination within the benefit structure). The reason for these observations can lie in the nature of analysed materials: greater environmental value of pozzolanic material natural resources - less accessibility compared to gypsum abundance, stronger environmental impact of disposed CFA (due to leaching of various elements including heavy metals and, consequently, the soil and groundwater contamination potential). All these factors have contributed to longer critical distances of fly ash transmission compared to the gypsum exchange.

Synthesizing results of environmental impact of symbiotic fly ash exchange from the perspective of various impact categories, it should be noted that a very wide range of the critical distance has been obtained $(279-14,645 \mathrm{~km})$. Since it is very difficult to compare the environmental impact associated with different endpoints, avoiding an arbitrary procedure of weighting, it could be assumed that the ultimate critical distance respecting all the results is the smallest value ( $279 \mathrm{~km}$ determined for category of resource). However, due to significant discrepancies between the figures, comprising almost two orders of magnitude, such as assumption would be controversial. From the perspective of other categories significant environmental benefits were reported for much longer distances. Setting the ultimate critical distance at $279 \mathrm{~km}$ would mean no recommendation for fly ash transmission over longer distance and ignoring environmental benefits associated with human health and resources. In order to solve the problem, a method applying the mixing triangle was used for further processing of results.

Figure 5a depicts the mixing triangle for the environmental impact comparison of the symbiotic fly ash transmission over the middle critical distance $(708 \mathrm{~km}$ obtained for ecosystem quality category) with the reference scenario assuming no symbiotic exchange. The yellow part of the triangle represents the area where the total environmental impact of industrial symbiosis is more positive compared to the reference scenario. Despite the distance being far longer than $d_{\mathrm{crR}}$, yellow colour predominates on the graph which means that the symbiotic initiative can be recommended for most weighting sets. The reference scenario can be recommended only for the very low weight coefficients assigned to the human health impact category. Using a set of weighting coefficients where this category has even ten times lower weight than others would be very controversial. Setting the ultimate critical distance of $708 \mathrm{~km}$ (or less) would mean ignoring environmental benefits associated with human health. It can be concluded that the critical distance, respecting all three endpoints, is longer.

By additional analysis and interpolation the critical distance has been determined for which half of the mixing triangle area indicated recommendation for symbiosis initiative (yellow area), and the second part (blue area) suggested that no symbiotic cooperation should be undertaken (see Figure $5 \mathrm{~b}$ ). The balance observed has been obtained for the relative distance of $4,300 \mathrm{~km}$. The ultimate critical distance taking into account environmental impact within all the categories can be assumed to be around this figure. It can be stated that for $d_{\mathrm{R}}>4,300 \mathrm{~km}$ industrial symbiosis involving fly ash transmission is not justified environmentally.

The mixing triangle method was also applied in the study concerning gypsum symbiotic exchange. The balance between the two areas was obtained for the critical distance of around $230 \mathrm{~km}$ [20]. As it was suggested previously, the reasons of the discrepancy between both critical distances may be due to the differences in the material characteristics: less accessibility of pozzolanic material natural resources and more significant environmental impact of fly ash disposed in landfill. Thanks to CFA use, the scarce resources extraction and heavy metal leaching (in landfill) has been avoided which can lead to greater environmental benefit in relation to gypsum utilization. To offset the greater benefit with the loss associated with transportation, the longer distance has been involved. 

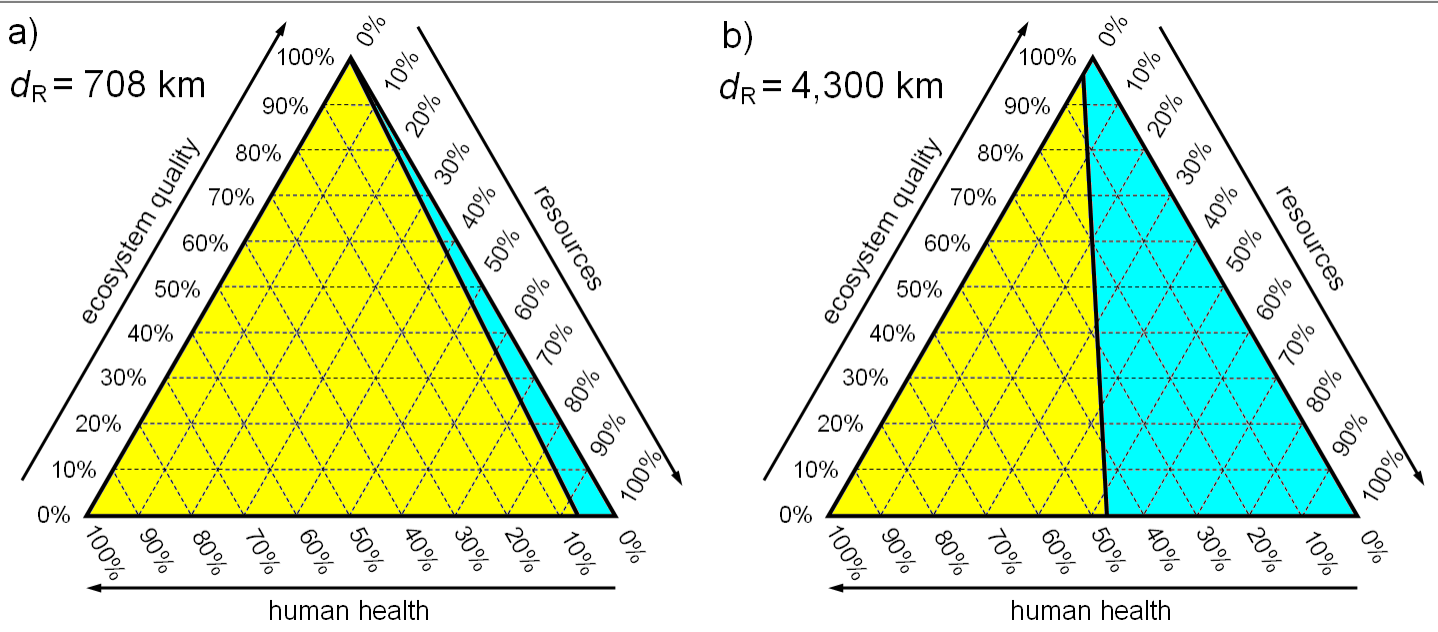

Figure 5. The mixing triangles for symbiotic fly ash exchange over a relative distance of $708 \mathrm{~km}$ and $4,300 \mathrm{~km}$

The determined distance may be sensitive to some assumptions of the research model. The transportation technology applied seems to be important factor affecting the results as there is a variety of means of transport differing significantly in environmental impact. This study assumes that CFA is transported by means of trucks with total permissible mass from the range of 3.5-28 t complying with standard EURO5, EURO4 or EURO3 with the proportion 1:1:1. Within the sensitivity analysis, the influence of the vehicle size, environmental standard and type of transport has been examined. However, according to the model applied, the amount of by-product transmitted has been proportional to environmental impact of all environmental balance components. Thus, regardless the fly ash amount, the result would be the same.

When it comes to sensitivity, various types of road transport have been analyzed to compare their impact on results. A dependence of vehicle size on the critical distance is observed. The results presented above assumed trucks with total permissible mass from the range of 7.5-32 $\mathrm{t}$ as a transport mean. Figure 6 depicts a relationship between vehicle size and critical distance. The assumption of the lightest trucks results in reduction of the critical distance by $57-64 \%$ (depending on the impact category) compared to the basic scenario, in case of the heaviest vehicles application, the critical distance is longer by $72-81 \%$. In case of heavy trucks $(>32 \mathrm{t})$ the critical distance is significantly longer (4-5 times) than in case of light ones $(<7.5 \mathrm{t})$. This results from environmental impact per transport unit (tkm). In order to transport the same amount of by-product, a longer distance must be covered by lighter vehicle that results in greater environmental impact. Figure 6 thus reveals the effect of scale of the chosen transport mean.

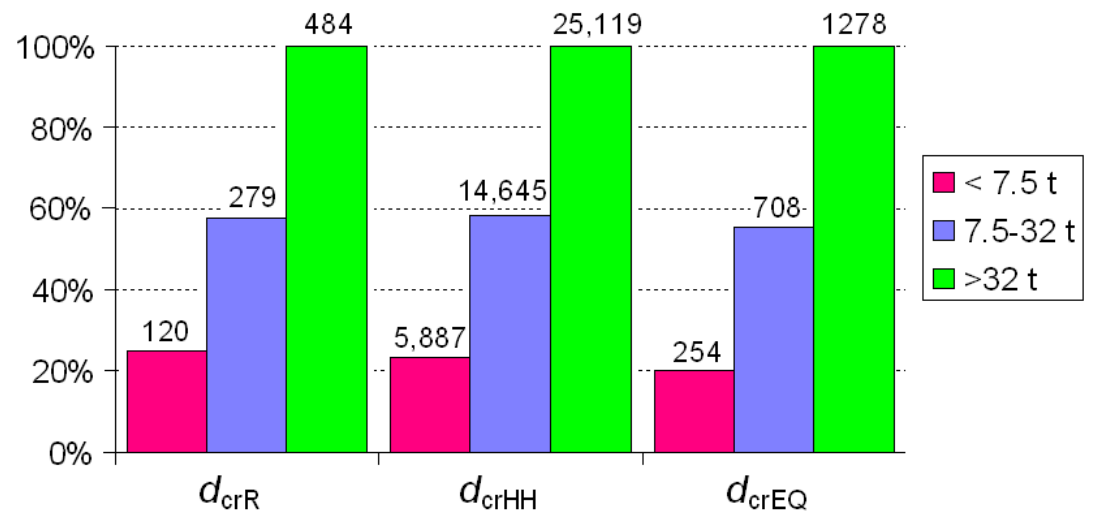

Figure 6. The dependence between vehicle size and critical distance [km] 
In case of gypsum symbiotic exchange, an analogous analysis of vehicle size was carried out. The critical distance was determined for trucks with permissible mass in three ranges: $<7.5 \mathrm{t}, 3.5-28 \mathrm{t}$ (the basic scenario), and $>16 \mathrm{t}$. The application of the lightest vehicles reduced the critical distance by 33-41\% (for different endpoints) in relation to the basic scenario. In case of the heaviest trucks use, in turn, the result was greater by 106-129\%. For heaviest (> $16 \mathrm{t}$ ) vehicles application the critical distance was 3-4 times longer than in case of the lightest trucks [20]. The smaller range of relative differences in the distances compared to that obtained for CFA exchange (4-5), was probably due to differences in mass ranges of the heaviest vehicles: $>16 \mathrm{t}$ (in case of gypsum) versus $>32 \mathrm{t}$ (in case of fly ash).

The environmental impact of symbiotic initiatives depends also on the type of drive applied. Figure 7 shows the effect of technology advancement (represented by European emission standard) on the critical distance. A general trend which is visible on the bar chart is very intuitive: the more green the drive, the longer the critical distance. This is most noticeably in case of impact categories of human health and ecosystem quality, the application of EURO 3 truck reduces the critical distance by $34 \%$ and $27 \%$, respectively, compared to EURO 5 vehicle. When it comes to resources category the reduction is not so significant (7\%). Moreover, in case of EURO 5 trucks the critical distance is slightly lower $(1 \%)$ than in case of less environmentally friendly EURO 4 vehicles. This can be explained by fuel consumption penalty phenomenon reported in literature which consists in increasing fuel consumption effect due to certain technologies that are used to control nitrogen oxide $\left(\mathrm{NO}_{\mathrm{x}}\right)$ emissions [31].

The comparison of data depicted in Figure 6 and Figure 7 shows that trucks size has more significant effect on environmental performance than vehicle emission standard. This conclusion leads to the further consideration of transport scale. Fichtner et al. [32] suggested to consider shifting the transportation from trucks to alternative carriers (railway, ship, etc.). The authors noticed that such a solution would require additional conditions, a railway station or a harbour should be in the same location as waste emitter. Following this idea, a simple approach has been developed to compare the results reported above with environmental impact of symbiotic fly ash exchange involving railroad and water transport, assuming that the conditions mentioned have been fulfilled.

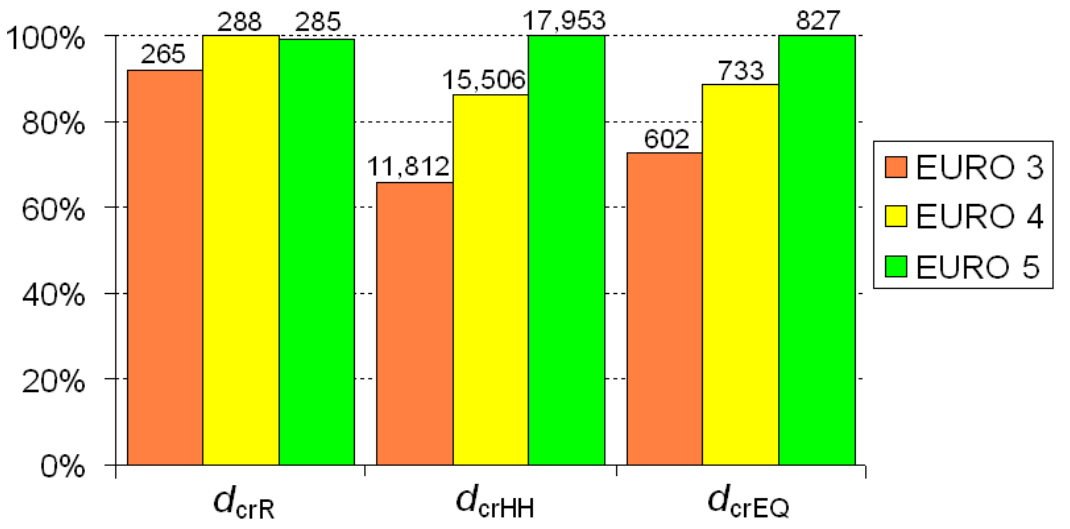

Figure 7. The effect of vehicle emission standard of the on critical distance [km]

Figure 8 depicts the critical distance for fly ash symbiotic exchange in case of road, railway and water transport. Results for road transport (pink bars) represent heavy duty vehicles with total permissible mass above $32 \mathrm{t}$ (see green bars in Figure 6). The railroad transport reflects an average performance of freight trains in Europe. The water transport is represented by a barge operating under European conditions. All compared means of transport are fuelled with diesel oil. The data obtained show that both train and barge 
achieved longer critical distance resulting from lower environmental impact compared to the road vehicles. The distance determined is 2.1-5.3 times longer in case of train and 1.5-3.1 times longer in case of barge compared to heavy duty trucks. Train seems to be the most recommendable transport solution. The greatest advantage is visible in the case of resources impact category: water and road transport have worse environmental performance by $42 \%$ and $81 \%$, respectively, compared to railroad transport.

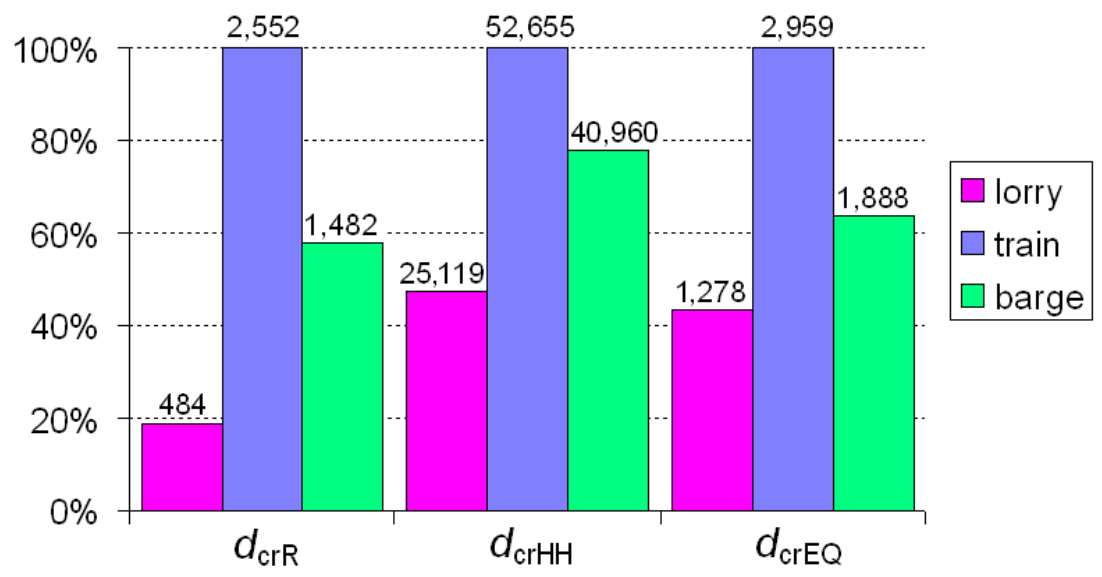

Figure 8 . The critical distance for road, railway and water transport [km]

The basic scenario of this study assumes no CFA pre-treatment. The aim of this paragraph is to examine the extent of environmental impact of the possible process of fly ash preparation for utilization as pozzolanic material in clinker production. Referring to the literature data, the analysis assumes that the main component of the processing environmental impact is electricity consumption in the amount of $5.7 \mathrm{kWh}$ per 1 ton of CFA [16]. In order to reflect European conditions, electricity mix for EU-27 is applied. Any other processes are assumed to have negligible impact. Table 1 presents the comparison of results determined assuming fly ash pre-treatment with results obtained for the basic scenario. As can be noticed, the distances involving electricity consumption are shorter. It is due to the negative impact of power generation and supply process. However, the differences between the respective figures are not significant. The greatest distance reduction, $2 \%$, occurs for the impact category of resources. The reason is the fossil fuel use by power stations. The results show that if the CFA was transmitted over 48 times shorter distance (around $6 \mathrm{~km}$ ), the resources depletion impact of the pre-treatment would achieve the level of transport impact. The total environmental impact of the symbiotic exchange would be twice as negative as separated transportation impact. For the other endpoint, the change does not exceed $1 \%$, thus the same effect would be observed at $14 \mathrm{~km}$ and $4 \mathrm{~km}$ for human health and ecosystem quality categories, respectively.

Table 1. Comparison of results for the scenario including pre-treatment and the basic scenario

\begin{tabular}{cccc}
\hline & \multicolumn{3}{c}{ Impact category } \\
\hline & Resources & Human health & Ecosystem quality \\
\hline$d_{\text {cr }}$ (basic scenario) $[\mathrm{km}]$ & 279 & 14,645 & 708 \\
$d_{\text {cr }}$ (with electricity use) $[\mathrm{km}]$ & 273.5 & 14,631 & 704 \\
$d_{\text {cr }}$ relative reduction [\%] & 2.0 & 0.1 & 0.6 \\
\hline
\end{tabular}

The analysis model including the environmental impact of by-product transport and pre-processing enables to compare the results obtained in this work with the outcomes reported by Dong et al. [16]. Apart from electricity consumption associated with CFA 
pre-treatment $(5.7 \mathrm{kWh} / \mathrm{t})$, the authors assumed that an average distance of CFA transport was $10 \mathrm{~km}$. The environmental impact was determined in terms of $\mathrm{CO}_{2}$ equivalent of greenhouse gas emission. Coal fly ash recycling provided $\mathrm{CO}_{2}$ emission reduction of $11,400 \mathrm{t} / \mathrm{y}$, but the additional energy consumption increased $\mathrm{CO}_{2}$ emission by $827.55 \mathrm{t} / \mathrm{y}$. To be able to compare the outcomes, a similar scenario has been applied in this study. The results have been expressed in terms of climate change category. The obtained characterization indicators reflected a similar proportion: the pre-processing energy consumption burden related to the impact of CFA recycling amounted to $8.1 \%$, whereas in the previous study the proportion reached $7.3 \%$. The slight difference indicates a high conformity between the researches.

\section{CONCLUSIONS}

The results presented in this paper confirm that the LCA method can be a useful tool for environmental impact assessment of symbiotic initiatives. The concepts of relative distance and critical distance seem to be helpful to reflect the environmental potential of industrial symbiosis.

Substantial differences between the results obtained for respective endpoints are observed. Various patterns of environmental impact for human health, ecosystem quality and resources categories result in marked differences in environmental benefit structure. Similar characteristics have been reported by Marcinkowski [20] for gypsum symbiotic transmission but particular positive components of the environmental balance played opposite roles there. Moreover, the range of critical distance was totally different (3.5-564 km compared to 279-14,645 km obtained here).

Application of the mixing triangle method proved to be very helpful in drawing consistent conclusions. The results obtained point out that the symbiotic initiatives consisting in the fly ash exchange using road transport can be environmentally justified at quite long distances measured in thousands of kilometers. The results reflect the effect of scale. Depending on individual impact category, the critical distance determined for heavy duty trucks, is 4-5 times longer than in case of lighter vehicles. In case of water and especially railroad transport the distance was significantly longer. At European level, thousands of kilometers mean that even international symbiotic initiatives can provide a benefit to the environment. The environmental benefit therefore exceeds economic profitability due to a low financial value of fly ash in relation to cost of transport over such a long distance. Thus, when profitable financially, fly ash exchange is justified from an environmental perspective.

Over time, more and more dynamic decline in the natural resources availability has been observed. If the accessibility of crude oil (needed for diesel production) is declining faster than the accessibility of natural pozzolanic resources, transport pressure on the environment could be expected to increase faster than the benefit of fly ash utilization. Then, the critical distance would decrease over time.

The opposite tendency could be predicted due to the progressive reduction in the environmental impact of vehicles over time (higher euro standards, increasingly common alternative-powered vehicles). However, the average increase of critical distance (15\%) resulting from the use of a vehicle meeting a higher emission standard indicates relatively slow progress in this field. Taking into consideration the time of introduction and validity of the standards EURO 3-EURO 5 (2000-2014), the average annual increase can be assessed at the level of $2 \%$.

\section{ACKNOWLEDGMENT}

The study was carried out within the statutory activity of the Faculty, project number 501-19-910-1-59-58: 'Ocena cyklu życia wybranych obiektów'. 


\section{REFERENCES}

1. Singh, A., Lou, H. H., Yaws, C. L., Hopper, J. R. and Pike, R. W., Environmental Impact Assessment of Different Design Schemes of an Industrial Ecosystem, Resources, Conservation and Recycling, Vol. 51, No. 2, pp 294-313, 2007, https://doi.org/10.1016/j.resconrec.2006.10.002

2. European Environment Agency, Circular Economy in Europe. Developing the Knowledge Base, EEA Report No. 2/2016, Publications Office of the European Union, Luxembourg, Luxembourg, 2016.

3. Chertow, M. R., "Uncovering" Industrial Symbiosis, Journal of Industrial Ecology, Vol. 11, No. 1, pp 11-30, 2007, https://doi.org/10.1162/jiec.2007.1110

4. Lowe, E. A., Creating by-product Resource Exchanges: Strategies for Eco-industrial Parks, Journal of Cleaner Production, Vol. 5, No. 1-2, pp 57-65, 1997, https://doi.org/10.1016/S0959-6526(97)00017-6

5. Mauthoor, S., Uncovering Industrial Symbiosis Potentials in a Small Island Developing State: The Case Study of Mauritius, Journal of Cleaner Production, Vol. 147, pp 506-513, 2017, https://doi.org/10.1016/j.jclepro.2017.01.138

6. Eckelman, M. J. and Chertow, M. R., Life Cycle Energy and Environmental Benefits of a US Industrial Symbiosis, Journal of Life Cycle Assessment, Vol. 18, No. 8, pp 1524-1532, 2013, https://doi.org/10.1007/s11367-013-0601-5

7. Rebitzer, G., Ekvall, T., Frischknecht, R., Hunkeler, D., Norris, G., Rydberg, T., Schmidt, W.-P., Suh, S., Weidema, B. P. and Pennington, D. W., Life Cycle Assessment Part 1: Framework, Goal and Scope Definition, Inventory Analysis, and Applications, Environment International, Vol. 30, No. 5, pp 701-720, 2004, https://doi.org/10.1016/j.envint.2003.11.005

8. Mattila, T., Pakarinen, S. and Sokka, L., Quantifying the Total Environmental Impacts of an Industrial Symbiosis A Comparison of Process-, Hybrid and Input-Output Life Cycle Assessment, Environmental Science and Technology, Vol. 44, No. 11, pp 4309-4314, 2010, https://doi.org/10.1021/es902673m

9. Sokka, L., Local Systems, Global Impacts. Using Life Cycle Assessment to Analyse the Potential and Constraints of Industrial Symbioses, JULKAISIJA - UTGIVARE, Helsinki, Finland, 2011.

10.Sokka, L., Melanen, M. and Nissinen, A., How Can the Sustainability of Industrial Symbioses be Measured? Progress in Industrial Ecology An International Journal, Vol. 5, No. 5/6, pp 518-535, 2008, https://doi.org/10.1504/PIE.2008.023414

11.Daddi, T., Nucci, B. and Iraldo, F., Using Life Cycle Assessment (LCA) to Measure the Environmental Benefits of Industrial Symbiosis in an Industrial Cluster of SMEs, Journal of Cleaner Production, Vol. 147, pp 157-164, 2017, https://doi.org/10.1016/j.jclepro.2017.01.090

12.Mattila, T., Lehtoranta, S., Sokka, L., Melanen, M. and Nissinen, A., Methodological Aspects of Applying Life Cycle Assessment to Industrial Symbioses, Journal of Industrial Ecology, Vol. 16, No. 1, pp 51-60, 2012, https://doi.org/10.1111/j.1530-9290.2011.00443.x

13. Yu, F., Han, F. and Cui, Z., Assessment of Life Cycle Environmental Benefits of an Industrial Symbiosis Cluster in China, Environmental Science and Pollution Research, Vol. 22, No. 7, pp 5511-5518, 2015, https://doi.org/10.1007/s11356-014-3712-z

14.Zhang, Y., Duan, S., Li, J., Shao, S., Wang, W. and Zhang, S., Life Cycle Assessment of Industrial Symbiosis in Songmudao Chemical Industrial Park, Dalian, China, Journal of Cleaner Production, Vol. 158, pp 192-199, 2017, https://doi.org/10.1016/j.jclepro.2017.04.119

15.Sokka, L., Lehtoranta, S., Nissinen, A. and Melanenet, M., Analyzing the Environmental Benefits of Industrial Symbiosis Life Cycle Assessment Applied to a Finnish Forest Industry Complex, Journal of Industrial Ecology, Vol. 15, No. 1, pp 137-155, 2010, https://doi.org/10.1111/j.1530-9290.2010.00276.x 
16.Dong, L., Liang, H., Zhang, L., Liu, Z., Gao, Z. and Hu, M., Highlighting Regional Eco-industrial Development: Life Cycle Benefits of an Urban Industrial Symbiosis and Implications in China, Ecological Modelling, Vol. 361, pp 164-176, 2017, https://doi.org/10.1016/j.ecolmodel.2017.07.032

17.Sun, L., Li, H., Dong, L., Fang, K., Ren, J., Geng, Y., Fujii, M., Zhangh, W., Zhang, N. and Liu, Z., Eco-benefits Assessment on Urban Industrial Symbiosis Based on Material Flows Analysis and Emergy Evaluation Approach: A Case of Liuzhou City, China, Resources, Conservation and Recycling, Vol. 119, pp 78-88, 2017, https://doi.org/10.1016/j.resconrec.2016.06.007

18.Deschamps, J., Simon, B., Tagnit-Hamou, A. and Amor, B., Is Open-loop Recycling the Lowest Preference in a Circular Economy? Answering Through LCA of Glass Powder in Concrete, Journal of Cleaner Production, Vol. 185, pp 14-22, 2018, https://doi.org/10.1016/j.jclepro.2018.03.021

19.Mohammed, F., Biswas, W. K., Yao, H. and Tade, M., Sustainability Assessment of Symbiotic Processes for the Reuse of Phosphogypsum, Journal of Cleaner Production, Vol. 188, pp 497-507, 2018, https://doi.org/10.1016/j.jclepro.2018.03.309

20.Marcinkowski, A., Environmental Efficiency of Industrial Symbiosis - LCA Case Study for Gypsum Exchange, Multidisciplinary Aspects of Production Engineering, Proceedings of the $X V$ International Conference Multidisciplinary Aspects of Production Engineering MAPE, Vol. 1, No. 1, pp 793-800, Zawiercie, Poland, 2018.

21.Ehrenfeld, J. and Gertler, N., Industrial Ecology in Practice: The Evolution of Interdependence at Kalundborg, Journal of Industrial Ecology, Vol. 1, No. 1, pp 67-79, 1997, https://doi.org/10.1162/jiec.1997.1.1.67

22.Sokka, L., Pakarinen, S. and Melanen, M., Industrial Symbiosis Contributing to More Sustainable Energy Use - An Example from the Forest Industry in Kymenlaakso, Finland, Journal of Cleaner Production, Vol. 19, No. 4, pp 285-293, 2011, https://doi.org/10.1016/j.jclepro.2009.08.014

23.Neves Santos, V. E. and Magrini, A., Biorefining and Industrial Symbiosis: A Proposal for Regional Development in Brazil, Journal of Cleaner Production, Vol. 177, pp 19-33, 2018, https://doi.org/10.1016/j.jclepro.2017.12.107

24.Wang, J., Zeng, Q., Zhao, J. and Wang, P., Eco-transformation Strategy for Traditional Industrial Parks in China: Perspectives from System Engineering Theory, Environmental Engineering \& Management Journal, Vol. 14, No. 10, pp 2309-2317, 2015, https://doi.org/10.30638/eemj.2015.246

25.EN 450-1:2012 Fly Ash for Concrete - Part 1: Definition, Specifications and Conformity Criteria, 2012.

26.Ahmaruzzman, M., A Review on the Utilization of Fly Ash, Progress in Energy and Combustion Science, Vol. 36, No. 3, pp 327-363, 2010, https://doi.org/10.1016/j.pecs.2009.11.003

27.Blissett, R. S. and Rowson, N. A., A Review of the Multi-component Utilisation of Coal Fly Ash, Fuel, Vol. 97, pp 1-23, 2012, https://doi.org/10.1016/j.fuel.2012.03.024

28.International Organization for Standardization, ISO 14040 Environmental Management - Life Cycle Assessment - Principles and Framework, 2006.

29.International Organization for Standardization, ISO 14044 Environmental Management - Life Cycle Assessment - Requirements and Guidelines, 2006.

30.Hofstetter, P., The Mixing Triangle: Correlation and Graphical Decision Support for LCA-based Comparisons, Journal of Industrial Ecology, Vol. 3, No. 4, pp 97-115, 1999, https://doi.org/10.1162/108819899569584

31.National Research Council of the National Academies, Technologies and Approaches to Reducing the Fuel Consumption of Medium- and Heavy-duty Vehicles, The National Academies Press, Washington, D. C., USA, p 55, 2010.

32.Fichtner, W., Tietze-Stöckinger, I., Frank, M. and Rentz, O., Barriers of Interorganisational Environmental Management: Two Case Studies on Industrial 
Symbiosis, Progress in Industrial Ecology - An International Journal, Vol. 2, No. 1, pp 73-88, 2005, https://doi.org/10.1504/PIE.2005.006778

Paper submitted: 25.10 .2018

Paper revised: 01.03.2019

Paper accepted: 01.03.2019 